\title{
Impact of tunable oligo-phosphonates on barium sulfate crystallization
}

\author{
Mark I. Ogden^, Colin L. Raston ${ }^{\#}$, Tomoko Radomirovic^, Franca Jones*^ \\ ${ }^{\wedge}$ Chemistry Department, Curtin University, GPO Box U1987, Perth WA 6845. \\ \# Centre for NanoScale Science and Technology, School of Chemical and Physical Sciences, Flinders University, Bedford Park, \\ SA 5042, Australia
}

\begin{abstract}
Calixarenes can be used as well-defined scaffolds for investigating structure-activity relationships of additives and their impact on crystallization. In this work we present the crystal growth modification of barium sulfate by $p$-phosphonic acid calix[n]arene, which vary in size, $\mathrm{n}=4,5,6$ and 8 , and thus vary in the size of the internal cavity for the same functionality in the upper rim. The tetrameric, hexameric and octameric macrocycles induce nanoparticle formation with clear superstructure. In the case of the hexameric calix[6]arene, the initial mesocrystalline superstructure fuses over time forming almost hollow spheres, while the mesocrystals formed in the presence of the tetramer and octamer are stable over an extended period. The pentameric calix[5]arene forms more disordered aggregates of single crystals. Thermogravimetric data show that a significant proportion of the weight of the barium sulfate containing solid is the macrocycle, regardless of the choice of macrocycle.
\end{abstract}

Keywords: crystallization, crystal growth modification, additives, calixarene, barium sulfate

Corresponding author contact details:

Chemistry Department, Curtin University, GPO Box U1987, Perth WA 6845.

Email:F.Jones@curtin.edu.au Phone: (618)92667677FFax: (618) 92664699 


\title{
Impact of tunable oligo-phosphonates on barium sulfate crystallization
}

\author{
Mark I. Ogden^, Colin L. Raston ${ }^{\#}$, Tomoko Radomirovic^, Franca Jones*^ \\ ^Chemistry Department, Curtin University, GPO Box U1987, Perth WA 6845. \\ \# Centre for NanoScale Science and Technology, School of Chemical and Physical Sciences, Flinders University, Bedford Park, \\ SA 5042, Australia
}

\begin{abstract}
Calixarenes can be used as well-defined scaffolds for investigating structure-activity relationships of additives and their impact on crystallization. In this work we present the crystal growth modification of barium sulfate by $p$-phosphonic acid calix[n]arene, which vary in size, $n=4,5,6$ and 8 , and thus vary in the size of the internal cavity for the same functionality in the upper rim. The tetrameric, hexameric and octameric macrocycles induce nanoparticle formation with clear superstructure. In the case of the hexameric calix[6]arene, the initial mesocrystalline superstructure fuses over time forming almost hollow spheres, while the mesocrystals formed in the presence of the tetramer and octamer are stable over an extended period. The pentameric calix[5]arene forms more disordered aggregates of single crystals. Thermogravimetric data show that a significant proportion of the weight of the barium sulfate containing solid is the macrocycle, regardless of the choice of macrocycle.
\end{abstract}

\section{Introduction}

Crystallization is important in many areas; for example, for industrial separation processes $^{1}$, for creating skeletal structures in organisms, ${ }^{2,3}$ and in geology. ${ }^{4,5}$ Much of the current interest in crystallization is, however, from a particle engineering perspective, ${ }^{6}$ mainly because particle size and shape can dramatically influence the properties of the material..$^{7,8}$ One strategy for controlling size and shape is to add impurities or crystal growth modifiers and much of the literature in this field is, in fact, related to how impurities impact on size and morphology of particles (for example 912). The fundamental structure-activity relationships governing inhibition efficacy, however, remain elusive although charge and lattice matching are known to be important criteria. ${ }^{13-15}$ Our work in this area has emphasised investigation of additives 
with systematic structural changes in order to better understand these structure-activity relationships. We have found, for instance, that functional groups influence the strength of adsorption to the surface and that this can lead to a loss of stability of the original structure of the resulting mesocrystal. ${ }^{16}$

Systematic investigation of the impact of functional groups on crystal growth requires a well understood crystalline substrate, and a readily modified additive structure. As a target for crystal growth studies, barium sulfate is a relatively simple system, having one known crystal structure at ambient temperatures and pressures, and is therefore often used as a model system. However, it is also a common scale (unwanted crystallization) compound in off-shore oil production, ${ }^{17,} 18$ and thus improved understanding of barium sulfate crystal growth is of industrial significance. In addition, it is found as a biomineral in some organisms ${ }^{19-21}$, and is of interest in the 'barite paradox' - barium sulfate crystallization in sea-water despite the sea-water being undersaturated. ${ }^{22,23}$

For additive design, the macrocyclic polyphenols known as calixarenes are very useful, as they can be readily functionalised with a wide range of groups which are known to have an impact on crystal growth of inorganic materials in general, and can be functionalised at the phenol (lower) rim, or in the para position relative to the phenol $\mathrm{O}$ atom in the so called upper rim (Figure 1). The resulting molecules exhibit a range of interesting behaviours in their own right, often tending to have selfassembling properties that lead to a wide range nanostructures ${ }^{24,25}$ that can induce macroscale phenomena such as hydrogelation, ${ }^{26}$ for example. We have previously shown that calixarenes functionalised at the lower phenolic rim, ${ }^{27}$ and at the upper rim, ${ }^{16,28}$ can be powerful inhibitors of barium sulphate crystallization. Some of these molecules have shown complex effects on crystallization whereby promotion is observed at low concentrations and inhibition at high concentrations. ${ }^{16,28} \mathrm{We}$ have shown that while phosphonate- (or phosphonic acid) and sulfonate-functionalised calixarene additives have similar impacts on barium sulfate morphology, their effect on crystallization are subtly different. ${ }^{16,28}$ All of these studies have focused on the tetrameric calix[4]arene, and hence do not fully exploit the flexibility of calixarene derivatives which can be readily accessed in larger ring sizes, particularly the pentamer, hexamer and octamer. As an initial investigation into the impact of 
macrocycle size, we present here the results from the study of four calix[n]arene-based additives, all phosphonated at the upper rim, for varying ring sizes, compounds $\mathbf{1}, \mathrm{n}=$ $4,2, n=5,3, n=6$ and $4, n=8$ (Figure 1). We compare and contrast their impact on barium sulfate crystallization and determine what impact the choice of macrocycle has on the crystallization.

\section{Methods and Materials}

All methods in this work are described in detail elsewhere ${ }^{14,16,27,28}$ and so only brief descriptions will be repeated here.

\section{Synthesis}

All calixarene molecules were synthesized in-house. They were: $p$-phosphonic acid calix[4] $\operatorname{arene}^{16}(\mathbf{1}), \quad p$-phosphonic acid calix[5] $\operatorname{arene}^{29}(\mathbf{2}), \quad p$-phosphonic acid calix[6] $\operatorname{arene}^{29}(3)$ and $p$-phosphonic acid calix[8]arene ${ }^{29}(4)$.

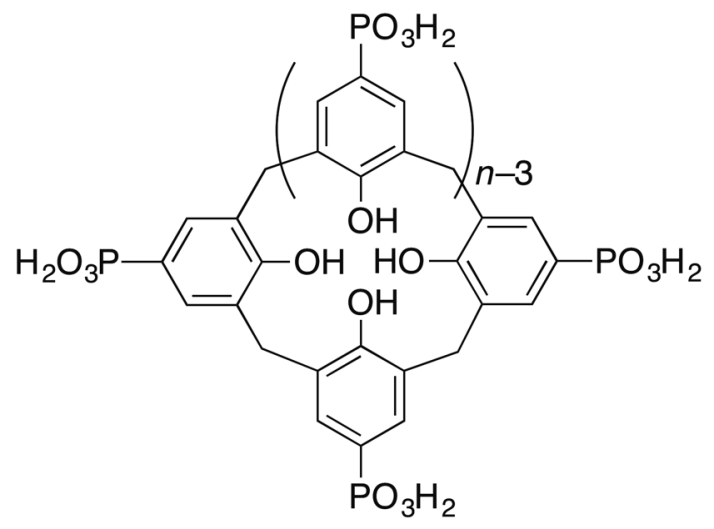

Figure 1. Chemical structure of the $p$-phosphonic acid calix $[n]$ arenes, where $n=4,5,6$, or 8 .

\section{Conductivity}

Unseeded, de-supersaturation curves were obtained by analysis of conductivity data. The method consists of equilibrating $0.249 \mathrm{mM} \mathrm{BaCl}_{2}$ and then adding the molar equivalent of $\mathrm{Na}_{2} \mathrm{SO}_{4}$ solution quickly with stirring to initiate crystallization. The linear region of the de-supersaturation curve was used to calculate the observed desupersaturation rate, $\mathrm{k}$. The $\mathrm{pH}$ for all experiments was 6.0 except where specified. The calixarenes were prepared as a stock solution of $1000 \mathrm{ppm}$, the $\mathrm{pH}$ of which was adjusted to 6.0 and the desired volume was added to the barium chloride solution prior 
to the addition of sulfate (keeping the total volume constant by adjusting the water addition). Supersaturation is defined as:

$$
\mathrm{S}=\mathrm{c} / \mathrm{c}_{\mathrm{o}}
$$

where $\mathrm{c}$ is the concentration of the ion and $\mathrm{c}_{\mathrm{o}}$ is the equilibrium solubility concentration. This approximation has been made because we do not know the extent of barium ion complexation with the calixarene molecules in question. In the absence of calixarene, the supersaturation ratio for the conductivity experiments is 25 . Conductivity studies showed negligible complexation for the [4]- and -[5]-calixarene molecules. At the highest concentration of the calix[8]arene the $S$ is expected to be 18 , at all other concentrations $S$ is expected to be in the range 22-25. Naturally, higher calixarene concentrations relate to lower $\mathbf{S}$ values. In addition, the data is normalized to the control value according to:

Normalised De-supersaturation rate $=\mathrm{k} / \mathrm{k}_{\mathrm{o}}$

where $\mathrm{k}_{\mathrm{o}}$ is the de-supersaturation rate in the absence of impurity and $\mathrm{k}$ is the desupersaturation rate for the experiment with impurity present. A value of 1 thus indicates no inhibition, while 0 indicates complete inhibition. Values greater than 1 represent promotion of crystallization compared to the control.

\section{Scanning and transmission electron microscopy (SEM/TEM)}

Samples were collected by filtration onto $0.22 \mu \mathrm{m}$ membranes and washed with ultrapure water before drying in a desiccator. A portion of the dried filter paper was placed onto carbon-coated stubs and samples were then gold sputtered prior to viewing in a Philips XL30 or Zeiss Evo scanning electron microscope.

Transmission electron microscopy was conducted on ultramicrotomed sections of solids collected and set into resin except for the $p$-phosphonic acid calix[8]arene; in this case the aged solids left in solution were directly pipetted onto the carbon coated TEM grid and the excess solution removed with an absorbent tissue. The samples were viewed on a Jeol 2011 instrument at $200 \mathrm{kV}$.

\section{Nephelometry}


Turbidity experiments were undertaken using a UV-Vis instrument operated at $900 \mathrm{~nm}$ using a quartz flow cell according to previous literature. The barium chloride concentration, sodium sulfate concentrations, $\mathrm{pH}$ and temperature were all equivalent to those used in the conductivity experiments. The flow rate through the cell was measured as being $67 \mathrm{~mL} / \mathrm{min}$ and this was achieved using a peristaltic pump.

\section{Atomic force microscopy (AFM)}

AFM experiments were performed on a PicoPlus instrument using a standard silicon nitride cantilever with a flow-through cell attachment. A freshly cleaved mineralogical barium sulfate sample was fixed to a metallic stub and flushed with filtered ultrapure water using a precision, dual syringe pump. One syringe had the water replaced with barium chloride solution $(0.1 \mathrm{mM})$ and the other with sodium sulfate solution $(0.1$ $\mathrm{mM}$ ) to obtain growth rates for the system without additives. Finally, the barium chloride solution was replaced with a solution containing barium chloride plus the calixarene molecule of interest at a known concentration and the sodium sulfate solution was topped up as necessary. In this way, the rate of growth of the original barium sulfate could be measured and the rate when calixarene was added could be compared.

\section{$X$-ray diffraction $(X R D)$}

Up-scaled, $4 \mathrm{~L}$ batches were prepared in order to obtain sufficient solids for X-ray diffraction analysis. The solids were collected by filtration on a $0.22 \mu \mathrm{m}$ membrane and washed with ultrapure water before drying in a desiccator. The XRD patterns were collected on a Bruker D8 Advance instrument using $\mathrm{Cu} \mathrm{K}_{\alpha}$ radiation and a low background holder, spinning at $30 \mathrm{rpm}$. The 2theta range was 15-50 degrees with a step size of $0.001^{\circ}$ and a divergence slit of $0.3^{\circ}$.

\section{Results}

\section{Conductivity}

The ability of the calixarene molecules to inhibit overall barium sulfate crystallization is slightly different depending on the size of the macrocycle (see Figure 2). The addition of $\mathbf{1}$ inhibits the barium sulfate crystallization reaction completely (over the 3 hour time period) at concentrations as low as $0.013-0.014 \mathrm{mM}$, while the 
pentamer 2 appears to have the greatest potency in terms of concentration. Given that these two calixarene molecules are not expected to complex barium ions appreciably, this inhibition activity cannot be ascribed to changes in supersaturation. Calix[6]arene $\mathbf{3}$ appears to be slightly less potent than $\mathbf{1}$ and $\mathbf{2}$, and the octamer $\mathbf{4}$ is the least potent of all as an inhibitor of barium sulfate crystallization. This is despite the fact that these two larger calixarene molecules (3 and 4) are expected to lower the supersaturation, and no doubt the inhibitory impact at high concentration is related to this. The inhibitory power of the calixarene molecules decreases (in terms of concentration required to inhibit) as the ring size increases, 2 excepted, despite the increased number of phosphonate groups present (4 versus 8 ), which can bind to the surface of the barium sulfate or indeed be incorporated into the material.

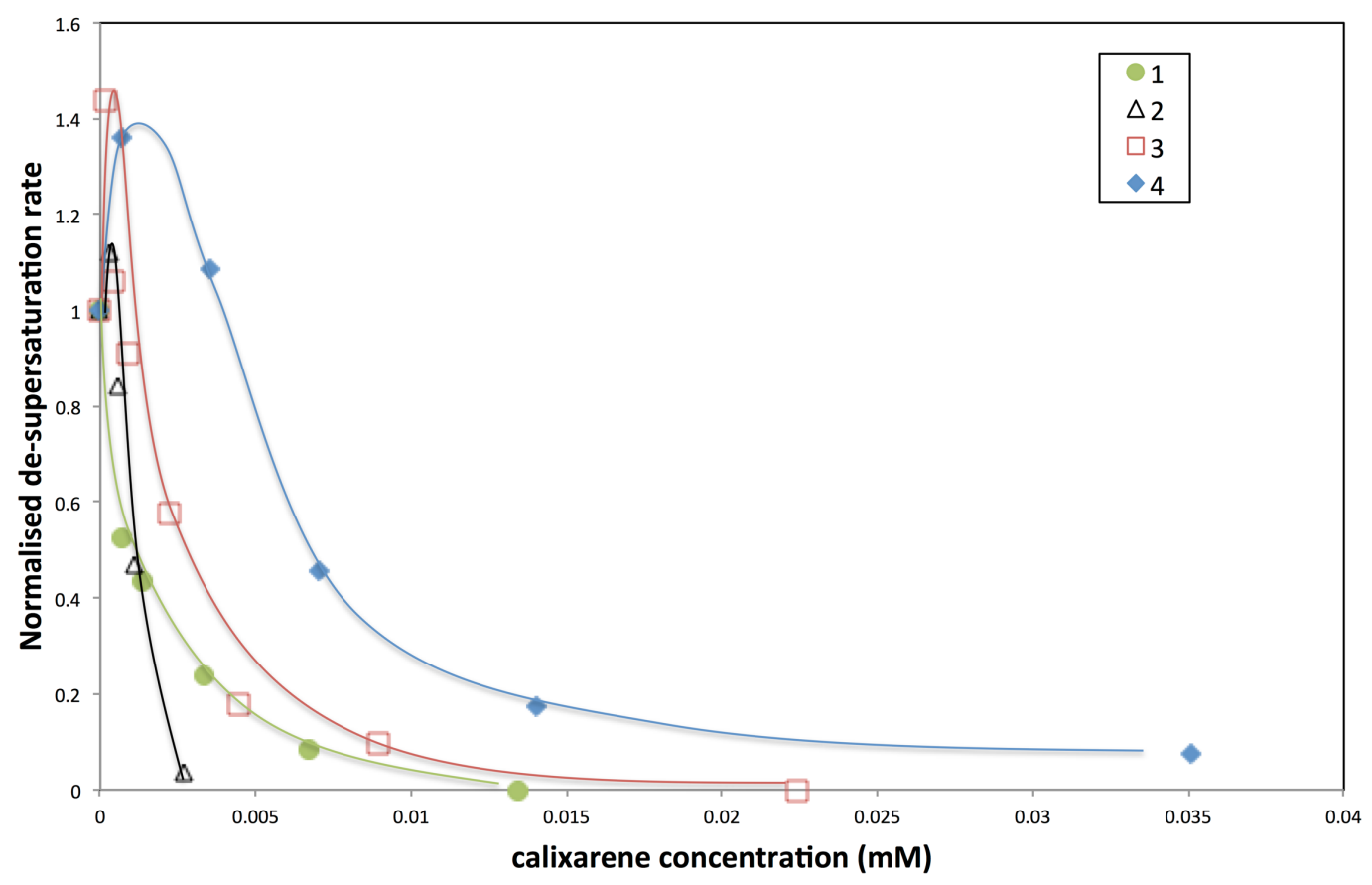

Figure 2. Normalised de-supersaturation rate of barium sulfate crystallization derived from conductivity experiments for the calixarene molecules. Closed circles correspond to the $p$-phosphonic acid calix[4]arene, 1, open triangles correspond to the $p$-phosphonic acid calix[5]arene, $\mathbf{2}$, open squares to the $p$-phosphonic acid calix[6]arene, $\mathbf{3}$ and closed diamonds to the $p$-phosphonic acid calix[8]arene, 4. Errors are $\pm 10 \%$ and lines are drawn to aid reader only. 
From the conductivity data (Figure 2 and SFig 1.) the presence of 2, 3 and 4 induces barium sulfate crystallization promotion at low concentrations. This is not observed when the $p$-phosphonic calix[4]arene (1) is present.

SEM

The morphology results for barium sulfate particles formed in the presence of $\mathbf{1}$ can be found in our previous papers ${ }^{16,28}$ and thus we discuss here the impact of 2, 3 and 4 only. Figure 3 shows the barium sulfate particles formed in the presence of $p$ phosphonic acid calix[5]arene (2) quickly become rounded, and eventually form nanoparticles, that appear, at this magnification, to be roughly spherical in shape. As the concentration of $\mathbf{2}$ increases the size of the barium sulfate particles decreases. At the highest concentration investigated the particles appear to be $\sim 300 \mathrm{~nm}$ in diameter.

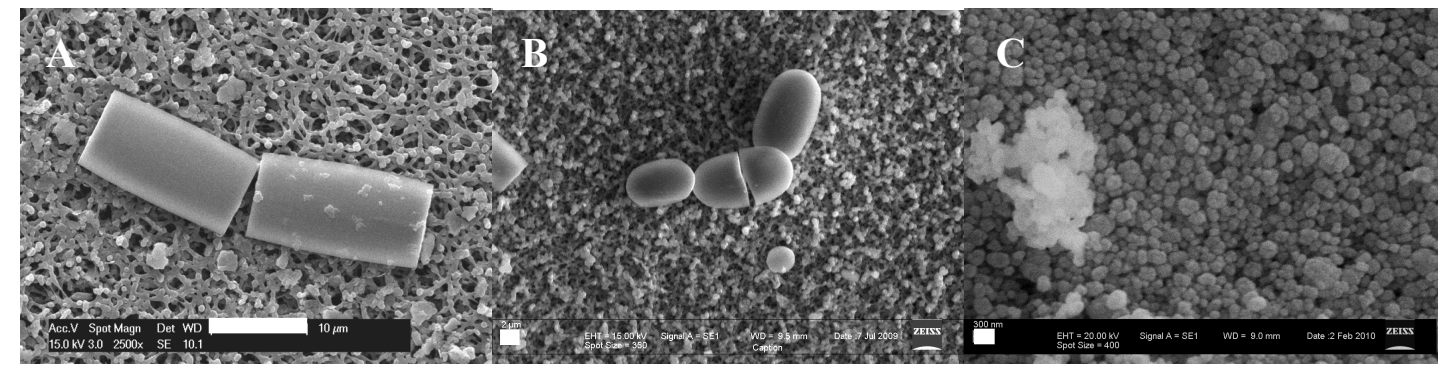

Figure 3. SEM images of barium sulfate formed in the presence of the $p$-phosphonic acid calix[5]arene, 2, (A) $0 \mathrm{mM}$ (B) $0.003 \mathrm{mM}$ and (C) $0.012 \mathrm{mM}$ (size bars for the images are $10 \mu \mathrm{m}, 2 \mu \mathrm{m}$ and $300 \mathrm{~nm}$ respectively).

The presence of the hexamer 3 also induces barium sulfate formation with rounded morphology (Figure 4) that finally appear to be spherical at higher concentrations. However, the initial morphology at low calixarene concentration appears to be highly roughened on the surface of similar morphology to the control but with a 1:1 aspect ratio. This suggests a decrease of the relative growth rate of the (001) face (or the $c$ axis) to the other faces. The size of the barium sulfate spherical particles is larger in the presence of the 3 than $2(\sim 2 \mu \mathrm{m}$ compared to $\sim 300 \mathrm{~nm})$ at almost equivalent concentrations. 


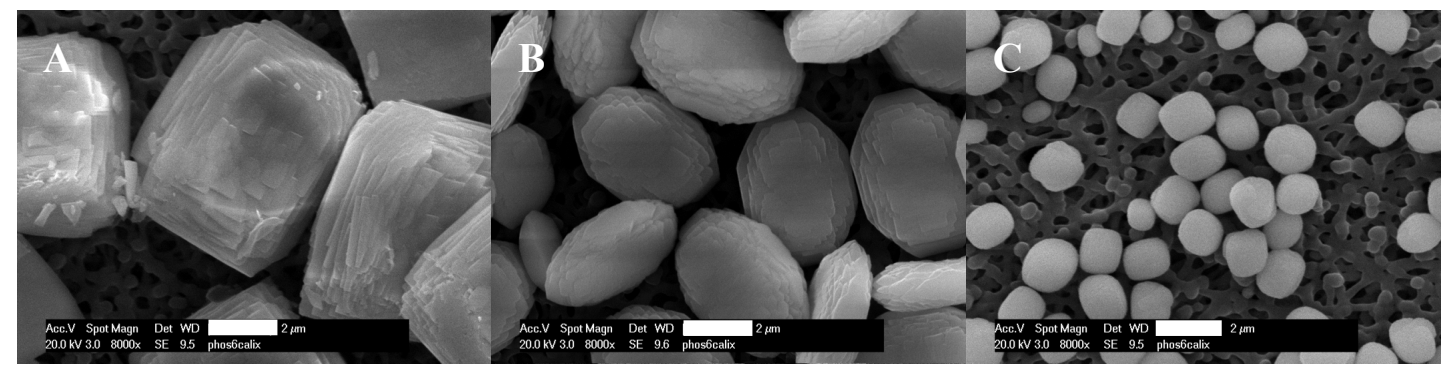

Figure 4. SEM images of barium sulfate particles formed in the presence of (A) $0.0003 \mathrm{mM}$ (B) 0.006 $\mathrm{mM}$ and (C) $0.011 \mathrm{mM}$ p-phosphonic acid calix[6]arene, 3, (size bars are all $2 \mu \mathrm{m}$ ).

Similarly, the presence of the octamer 4 also appears to result in the formation of small spherical particles, and at the higher concentrations the spherical particles are unchanged but appear to be intermixed with an amorphous component (see Figure 5B\&C). At lower concentrations, the three calixarenes, $2-4$, have their own unique impact on barium sulfate morphology. Smooth and rounded particles are observed for $\mathbf{2}$, roughening of the $\mathrm{hk} 0$ barium sulfate faces with an aspect ratio of $1: 1$ for $\mathbf{3}$, and round disc-like inter-grown particles for 4.

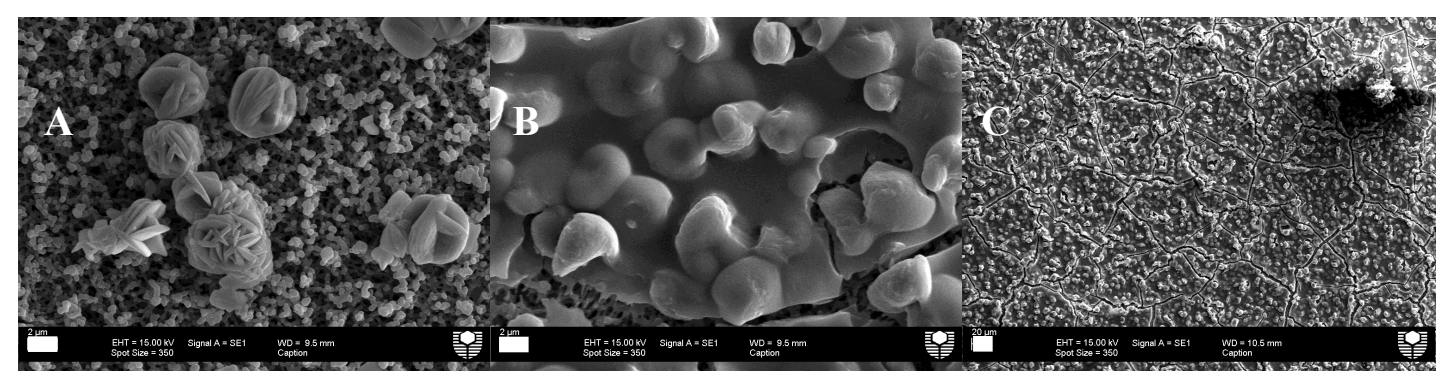

Figure 5. SEM images of barium sulfate particles formed in the presence of (A) $0.003 \mathrm{mM}$ (B) 0.013 $\mathrm{mM}$ and (C) $0.033 \mathrm{mM}$ p-phosphonic acid calix[8]arene, 4, (size bars are all $2 \mu \mathrm{m}$, except $\mathrm{C}$ where the bar represents $20 \mu \mathrm{m})$.

\section{TEM}

Single crystals of barium sulfate formed in the presence of pentamer 2 , are evident using TEM (Figure 6a). In the aforementioned SEM images, the 'spherical' aggregates of barium sulfate formed in the presence of 2 are $\sim 300 \mathrm{~nm}$ in diameter. These correspond to an aggregate roughly the size shown by the white circle in Figure 6A. Thus, while aggregation appears to occur in the presence of $\mathbf{2}$, it does not appear to be occurring via an oriented mechanism. The TEM images (Figure 6B) show that in the 
presence of 3, aggregated structures of smaller particles are observed (further images can be seen in the supplementary information, SFig 2). In the case of 4 we were not able to observe the larger structures as the amorphous layer was very sensitive to beam damage (see supplementary information, SFig 2), and the $2 \mu \mathrm{m}$ particles were too dense and large to be observed in the TEM, and thus only the smaller particles were imaged. These images show that the barium sulfate particles (in the presence of 4) are formed from even smaller particles and when compared to the SEM images, where superstructures are evidenced (round disc like particles $\sim 1-2 \mu \mathrm{m}$ in diameter), this suggests that the superstructures are meso-crystals, as found for barium sulfate formed in the presence of $\mathbf{1}^{16,28}$.

Interestingly, some barium sulfate particles formed in the presence of $\mathbf{2}$ have a hexagonal shape and showed the same zone axis as that observed in the presence of $\mathbf{3}$ (blue circle, Figure 6A and B). The TEM images of barium sulfate formed in the presence of $\mathbf{3}$ show the particles are assembled in a non-random way with the SAED pattern exhibiting spots but with some mismatch caused by small misalignments. The zone observed in the SAED appears to be the $c$-axis. Clarification of the elongated direction for the system when $p$-phosphonic acid calix[5] arene (2) is present cannot be made as the diagonals of the hexagons are of different sizes and different angles, making the assignment inconclusive. Assuming, however, that the zone observed in the TEM is the $<001>$ and the diagonals are (210) faces, then elongation would presumably be in the $<010>$ direction. For barium sulfate formed in the presence of 4 the particles showed the same zone axis again (see Figure 6F). 

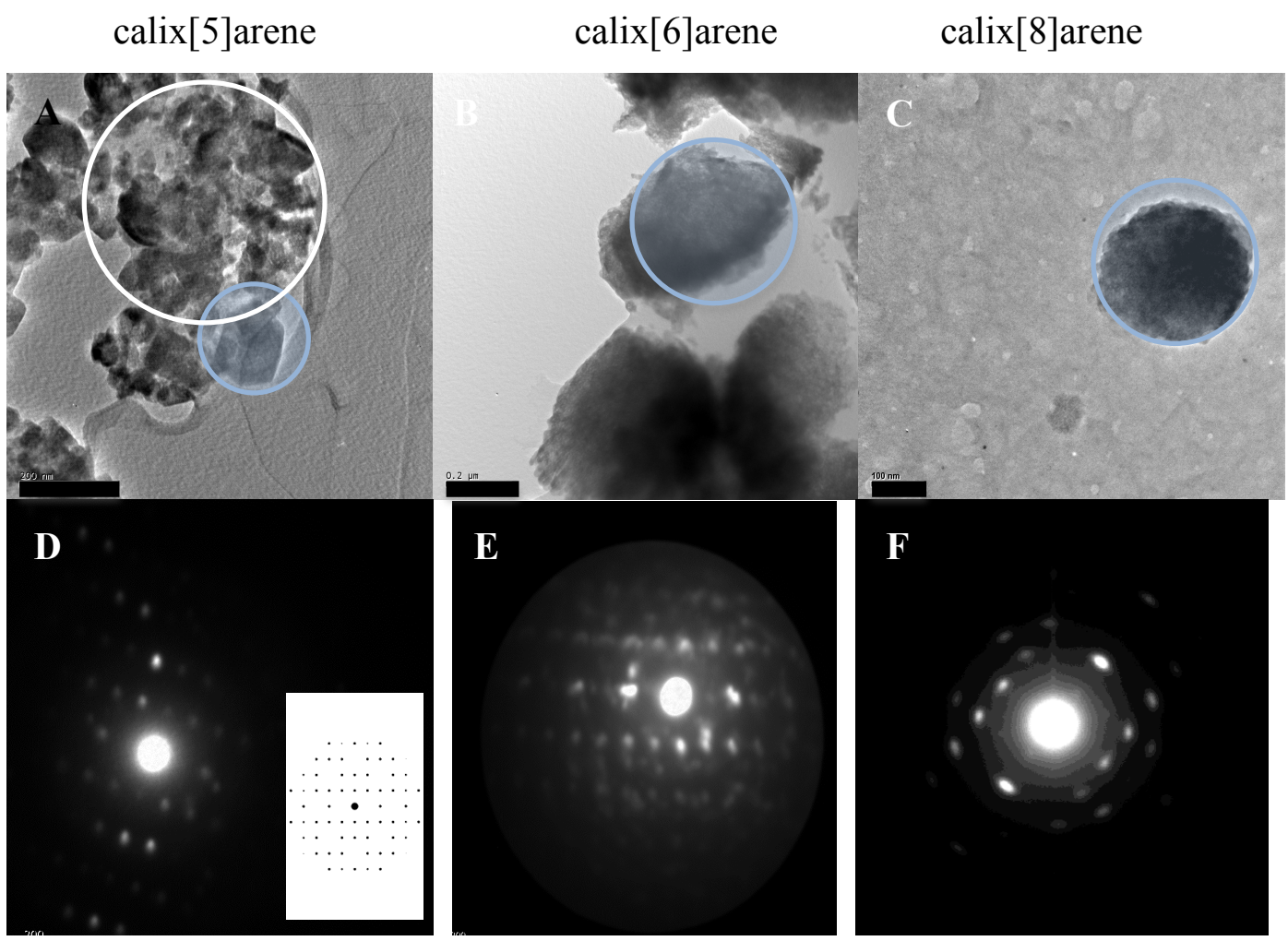

Figure 6. TEM images of barium sulfate formed in the presence of (A) 2, p-phosphonic acid calix[5] arene (0.015 mM) (B) 3, p-phosphonic acid calix[6]arene (0.02 mM), (C) 4, p-phosphonic calix[8]arene $(0.007 \mathrm{mM})$, and (D) $(\mathbf{E})$ and $(\mathbf{F})$ are the SAED of particles shown in the blue circles. Inset is the theoretical SAED for the (001) zone using SingleCrystal ${ }^{\circledR}$ (scale bars are $200 \mathrm{~nm}$ for (A) and (B) and $100 \mathrm{~nm}$ for (C)).

\section{XRD}

The XRD pattern for barium sulfate formed in the presence of $\mathbf{1}$ can be found in ref. 16. The XRD patterns show the presence of barium sulfate as the solid phase formed in all circumstances. However, the peaks are noticeably broadened in comparison to the control. ${ }^{16}$ Using the 211 peak, the expected crystallite size based on the peak width analysis is $\sim 100 \mathrm{~nm}$ when $\mathbf{2}$ and $\mathbf{4}$ are present, and $\sim 85 \mathrm{~nm}$ when $\mathbf{3}$ is present. 

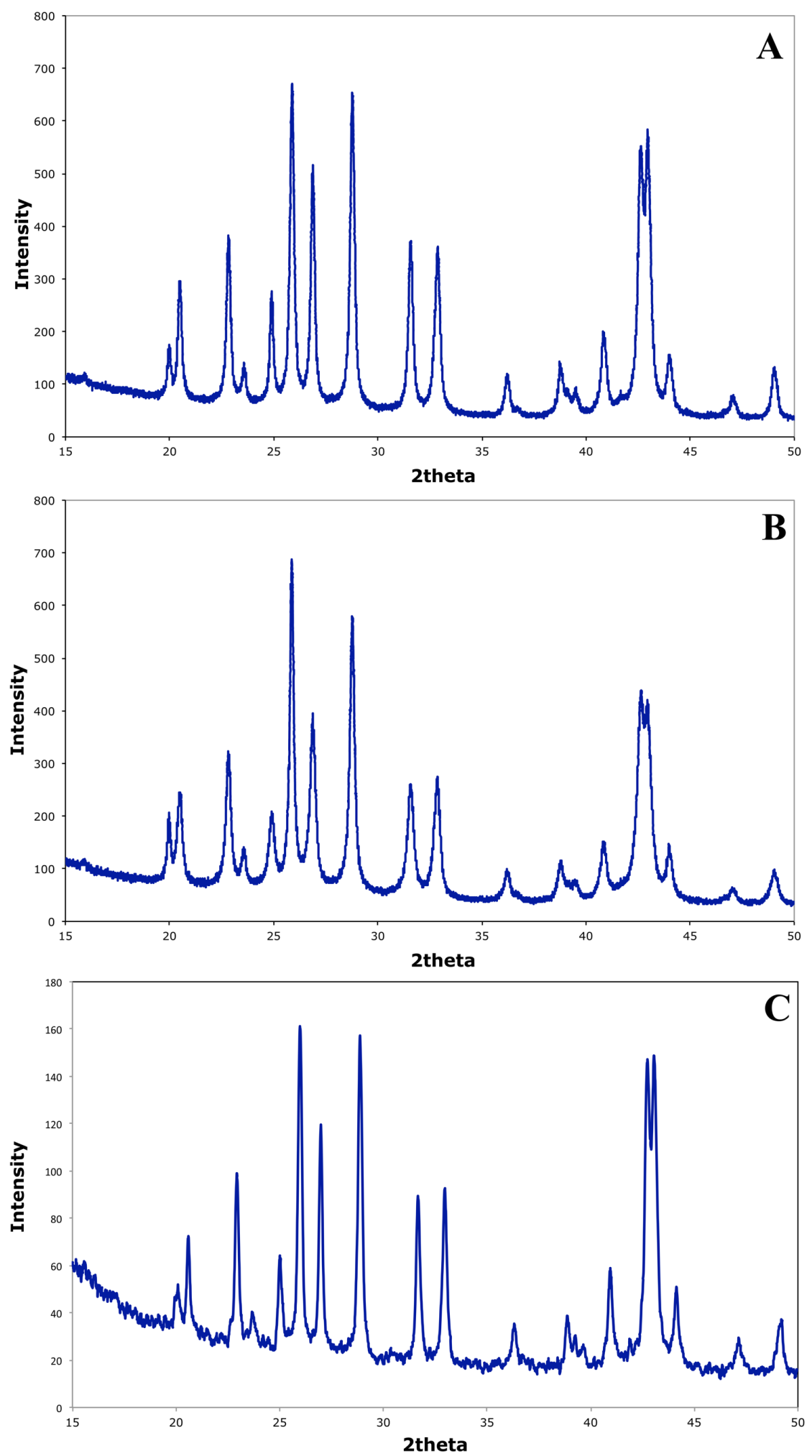

Figure 7. Powder XRD patterns of barite precipitated in the presence of (A) $0.015 \mathrm{mM}, p$-phosphonic acid calix[5]arene, 2, (B) $0.02 \mathrm{mM} p$-phosphonic acid calix[6]arene, 3, and (C) $0.007 \mathrm{mM}$-phosphonic acid calix[8]arene, 4. 
The individual particles formed in the presence of $\mathbf{2}$ vary from $50-200 \mathrm{~nm}$ in diameter, based on the TEM images, which is consistent with a crystallite size of $\sim 100 \mathrm{~nm}$. This is not the case for 3 where the barium sulfate spheres are about $500 \mathrm{~nm}$ in radius as can be observed in the SEM and TEM images (Figure 4 and Figure 6). However, the spheres formed in the presence of $\mathbf{3}$ are made up of smaller particles as already discussed (see supplementary information SFig 2) which range from 50 to $100 \mathrm{~nm}$ in length. Thus, the linewidth analysis is consistent with the size of these primary particles, which are then radially aggregating to form the larger spheres. The presence of 4 gives barium sulfate particles that are of the order of $\sim 1-2 \mu \mathrm{m}$ in diameter, as established from SEM images. However, the TEM images also clearly show (Figure 6C and supplementary information SFig 2) the presence of smaller particles. Despite the fact that these particles are $<<100 \mathrm{~nm}$ from the TEM images, they do not appear to be influencing the XRD pattern, and in particular the peak widths and crystallite size calculation. However, the line-width analysis result of $100 \mathrm{~nm}$ does correspond to the small spherical particles as shown in Figure 6C and to the disc-like particles observed in the SEM of the sample used for the XRD analysis (see supplementary information, SFig 3), which shows that the barium sulfate particles are approximately $1-2 \mu \mathrm{m}$ in diameter. Since the TEM and XRD results both suggest these particles are made up of smaller particles, and that these are aggregating in a defined way, this confirms the existence of mesocrystals in this case.

\section{Nephelometry}

The measurement of absorbance at $900 \mathrm{~nm}$ can be interpreted as a turbidity value ${ }^{30}$ and used to measure the induction time ${ }^{31}$, which is inversely related to the homogenous nucleation rate. The nephelometry results for barium sulfate crystallization in the presence of $\mathbf{1}$ can be found in ref 28 but are reproduced in the supplementary information (SFig 4). Essentially they show that the calix[4]arene is interacting with the critical nuclei and changing the surface free energy of these nuclei by increasing the induction time ${ }^{31}$.

As when $p$-phosphonic acid calix[4]arene (1) is present during crystallization, the presence of 3 also causes a lengthening of the barium sulfate crystallization induction time (Figure 8). The presence of $\mathbf{3}$ also induces different behaviour at low concentrations whereby the turbidity increases above that of the control. However, the 
turbidity is related both to particle number and size and these two effects cannot be decoupled, thus further information on this will have to be obtained from other techniques. The presence of $\mathbf{2}$ also increases the induction time and appears to be the most potent in inhibiting nucleation (in terms of concentration required) and altering the surface free energy of the critical nuclei. When 4 is present there is also inhibition with higher concentrations but also the same behaviour as $\mathbf{3}$ whereby the scattering increases relative to the control. Clearly, all of the $p$-phosphonic acid calix[n]arene molecules are 3D nucleation inhibitors, with 2 being the most active when the concentration is $>5 \mu \mathrm{M}$.

\section{$A F M$}

AFM allows the in-situ observation of $2 \mathrm{D}$ nucleation processes when conducted below the homogenous nucleation threshold. It also allows measuring the $2 \mathrm{D}$ island growth rates both in the presence and absence of the calix[n]arene molecules. While this is desirable, it should be noted that the results pertain only to the face in question and do not necessarily relate to the crystal as a whole. The growth rate was calculated along the slowest growth direction for barium sulfate growth islands, notably the $<100>$ direction. 


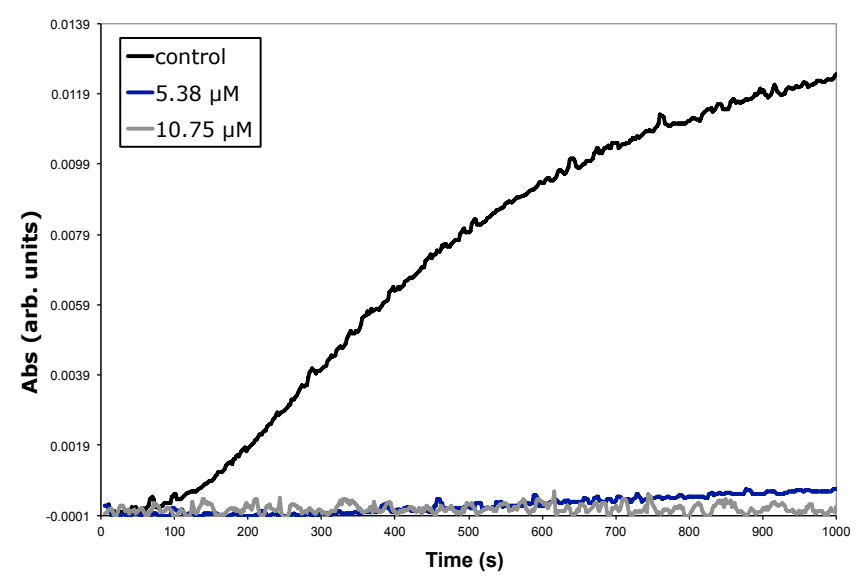

A
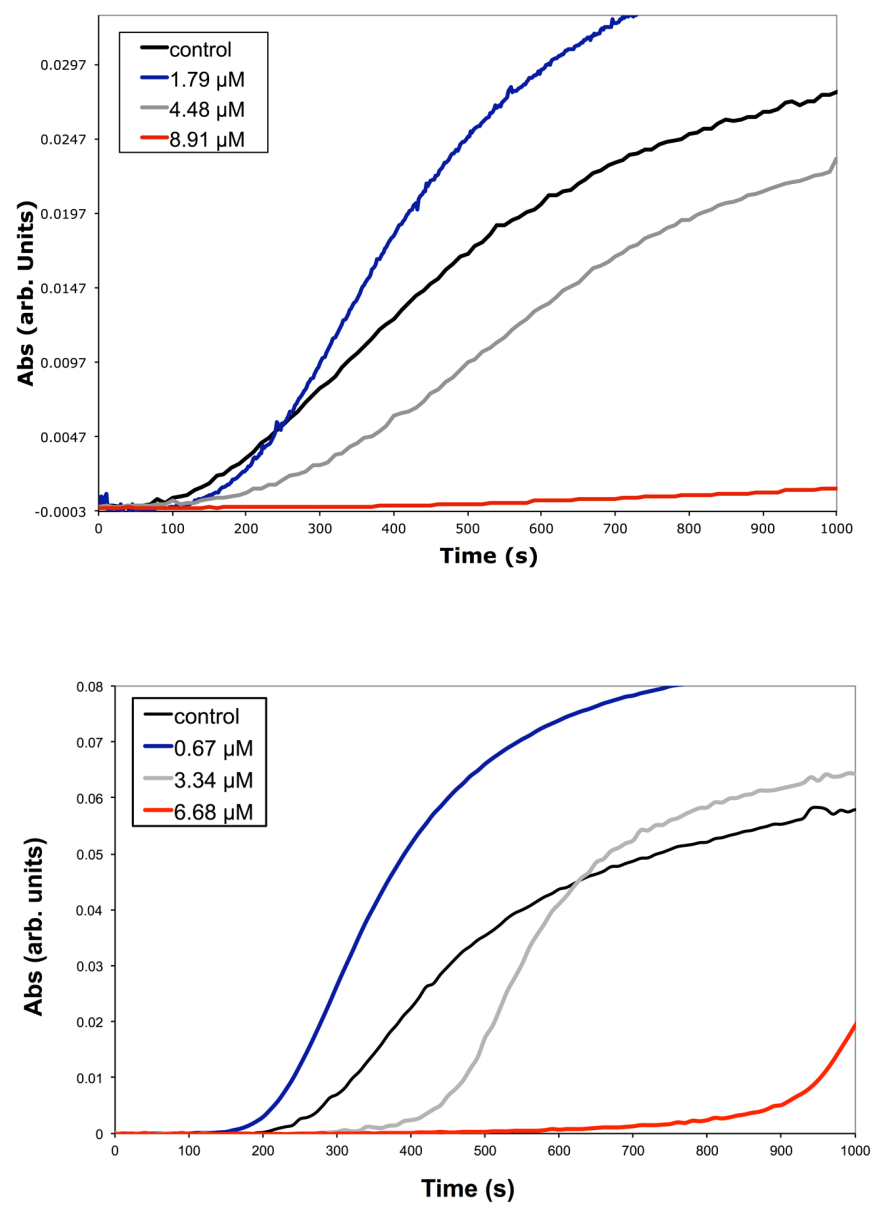

Figure 8. Absorbance versus time curves for barium sulfate crystallization in the presence of different concentrations of the calixarene molecules, (A) $p$-phosphonic acid calix[5] arene, 2, (B) $p$-phosphonic acid calix[6]arene, 3, and (C) p-phosphonic acid calix[8]arene, 4.

Measuring the growth rates in the presence of $\mathbf{2}$ was rather difficult. At very low concentrations the rate was not significantly different to the control while at concentrations ranging from $0.0002-0.001 \mathrm{mM}$ the nucleation rate increased substantially, and finding isolated nuclei to measure the growth rates was not possible 
(see Figure 9B and Figure 10A). Thus the impact of the $p$-phosphonic acid calix[5]arene (2) on the growth rate of the $<100>$ direction of barium sulfate (Figure $10 \mathrm{~A})$ is unresolved.
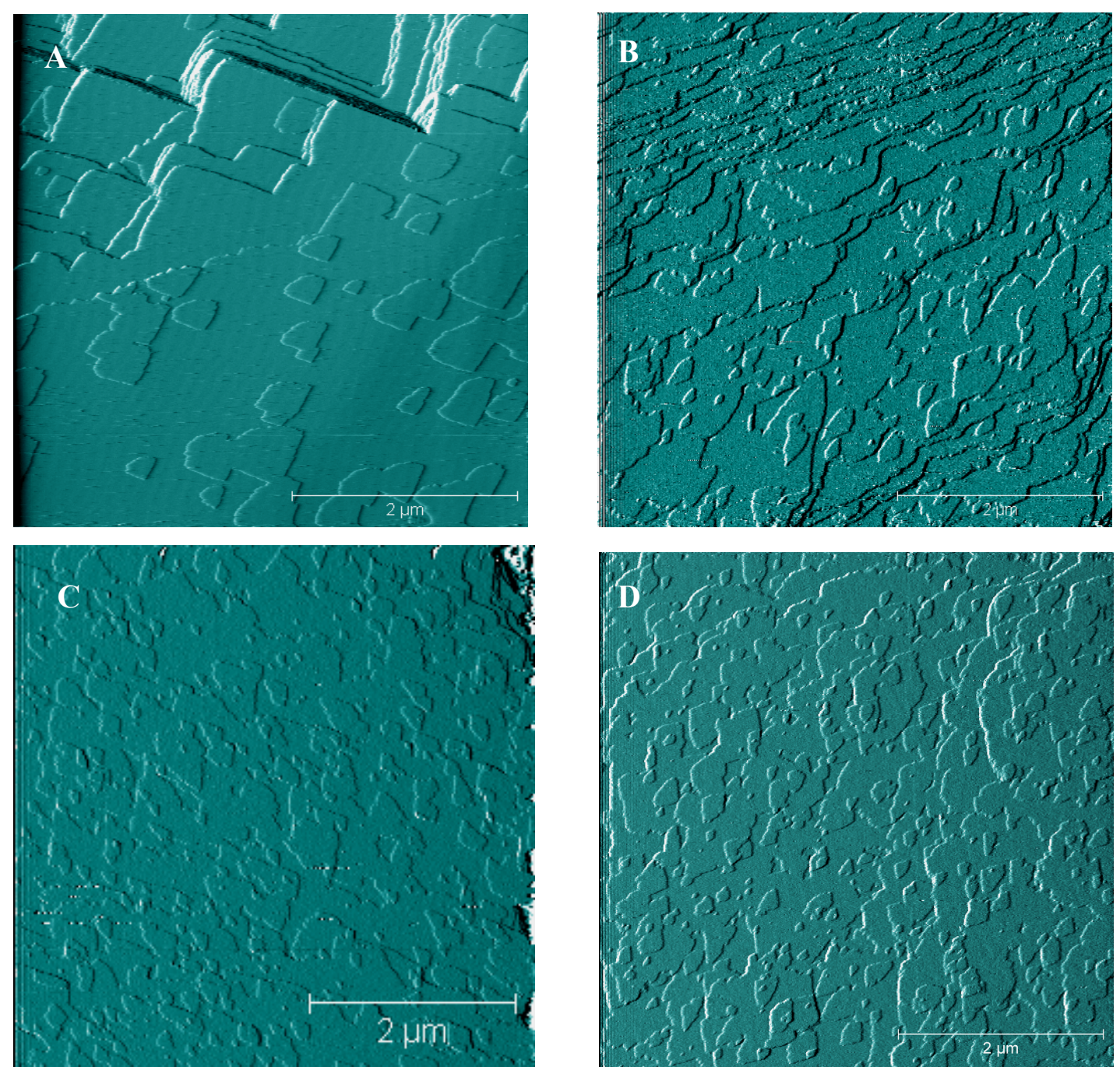

Figure 9. AFM images of the barite (001) face in (A) the absence of any additives, (B) in the presence of $p$ phosphonato calix[5] arene at $0.0018 \mathrm{mM}, \mathbf{2}, \mathbf{( C )}$, in the presence of $p$-phosphonic acid calix[6]arene at $0.0009 \mathrm{mM}, \mathbf{3}$, and (D) in the presence of $p$-phosphonic acid calix[8]arene, 4, at 0.0005 mM.

On a different crystal with defect lines, the action of $\mathbf{2}$ appeared to be to promote nucleation at defects (supplementary information, SFig 5.). At higher concentrations of 2 , inhibition of barium sulfate growth on the (001) face was observed.

A high barium sulfate 2D nucleation rate was also observed in the presence of $\mathbf{3}$ (see Figure 9C) but this appeared to result in a lower growth rate relative to the control (see 
Figure 10B). This behaviour is consistent with the SEM images in the presence of the p-phosphonic acid calix[6]arene (3) at lower concentrations, with roughened particles with a 1:1 aspect ratio, suggesting an (001) growth rate for barium sulfate that is lower than the control (where the aspect ratio is $\sim 2: 1$ ).

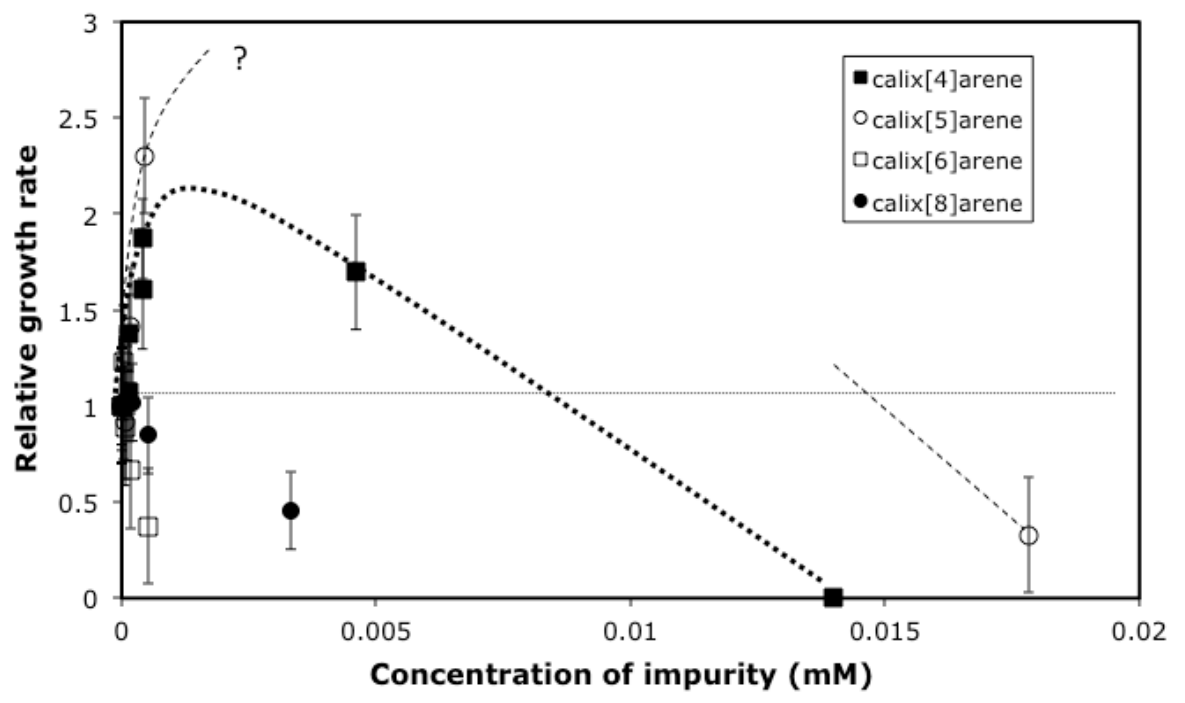

(A)

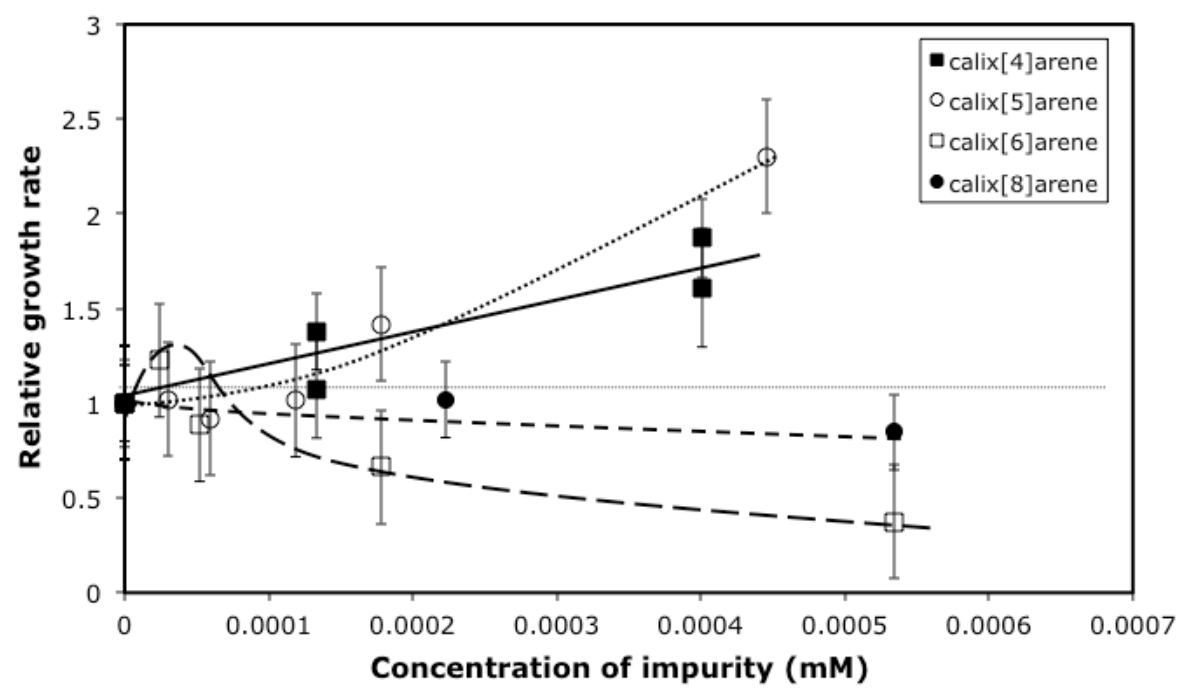

(B)

Figure 10. (A) Normalised growth rates in the $<100>$ direction of the barium sulfate (001) face in the presence of the $p$-phosphonic acid calix[n]arene. Lines drawn to aid reader only (B) Same as Figure 10 (a) but enlarging the $0-0.0007 \mathrm{mM}$ region. Lines drawn to aid reader only.

The presence of $\mathbf{4}$ caused similar effects to that of $\mathbf{3}$, with high 2D nucleation rates but lower growth rates for the $<100>$ of barium sulfate. Overall, the AFM images show that none of the phosphonated calixarene molecules change the $2 \mathrm{D}$ growth island 
shape appreciably but the islands do appear roughened when nucleation increases significantly.

Atomic resolution images (Figure 11) of the (001) barium sulfate surface in the presence of $\mathbf{2}$ and $\mathbf{3}$ were obtained in order to investigate further the interaction of the calixarene molecule with the surface (atomic resolution image when $\mathbf{1}$ is present can be found in ref. 16). The barium sulfate surface in the presence of the $p$-phosphonic acid calix[4]arene (1) has a $\sim 12.0 \times 6.2 \AA$ repeat unit structure, while for the $p$ phosphonic acid calix[5]arene (2) this changes slightly to $\sim 12.5$ x $8 \AA$. The barium sulfate surface in the presence of $p$-phosphonic acid calix[6]arene (3) is distinctly different to that for the presence of the other calixarenes, showing a much larger repeat structure of $45-50 \times 16 \AA$. There appears to be a ridge at the half repeat distance of $22-$ $25 \AA$ in the surface structure. Attempts to obtain atomic resolution images in the presence of the $p$-phosphonic acid calix[8]arene (4) were unsuccessful, the best image obtainable having a repeat unit of $10 \AA$, but this was only visible in the fourier transform of the scanned image (supplementary information, SFig. 6).

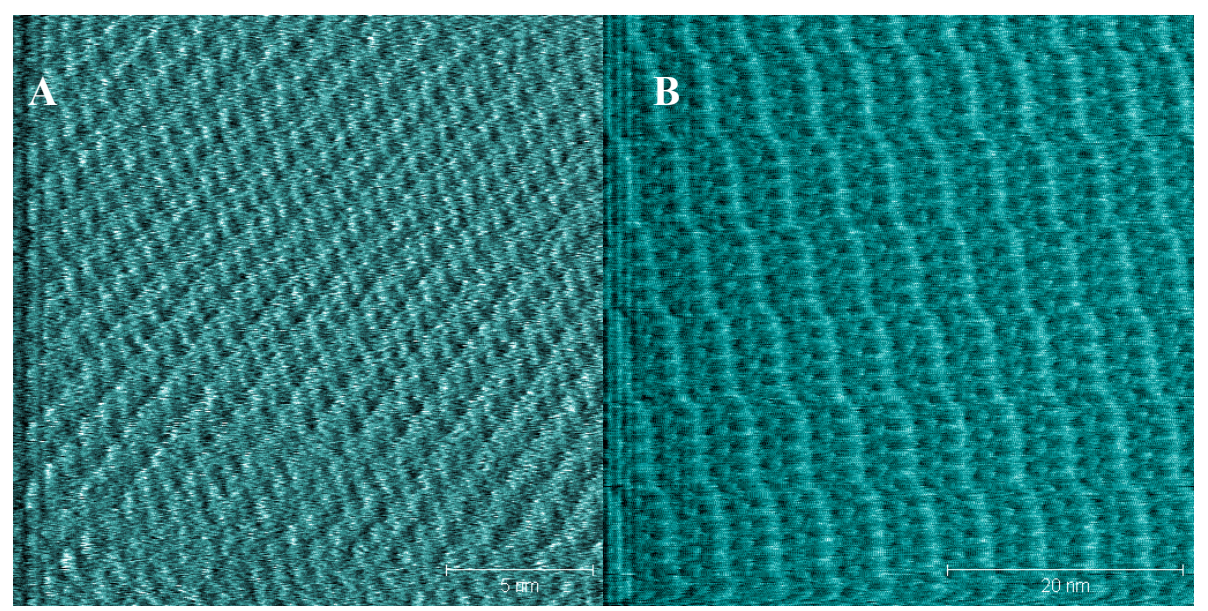

Figure 11. AFM atomic resolution images of the (001) face of barium sulfate in the presence of (A) $p$ phosphonic acid calix[5]arene, $2(0.0018 \mathrm{mM})$ and (B) p-phosphonic acid calix[6]arene, 3 (0.0009 $\mathrm{mM})$.

The surface structure observed in the case of $\mathbf{2}$, is similar to that reported previously for $\mathbf{1}$, but with a slightly larger repeat unit as might be expected. This suggests that both form a bilayer type structure, as often found with these macrocycles ${ }^{25,32}$. 
In the case of 3 the surface structure has a repeat unit of $45 \AA$ that is similar to that found by Houmadi et al. (50 $\AA)^{33}$ for the four layered structure they observed in the presence of a $p$-sulfonatocalix[6]arene. In addition, a crystalline calcium compound with the $p$-phosphonatocalix[6] arene has a unit cell, $a=14.0340, b=16.2130, c=$ $19.4062 \AA .{ }^{34}$ The half repeat value of $22-25 \AA$ and the $16 \AA$ for the atomic resolution image shown in Figure 11 are comparable to the $c$ and $b$ value respectively of the calcium structure, especially given that an analogous barium compound would be likely to form a larger unit cell compared to a calcium compound.

\section{Discussion}

The results from XRD and TEM confirm the barium sulfate particles formed in the presence of the $p$-phosphonic acid calix[4]arene, $\mathbf{1}$, as being meso-crystals ${ }^{16,28}$. Mesocrystals are defined to be crystals that appear to diffract as a single crystal but are, in fact, made up of self-assembled nanoparticles ${ }^{35,36}$. Their formation cannot be explained by classical crystallization theory and generally involves a core particle around which the initially formed nanoparticles aggregate in an oriented fashion. An important aspect of the meso-crystal formation mechanism is the stabilisation of the nanoparticles so that they have time to aggregate in this non-random superstructure. The group of Cölfen ${ }^{37-39}$ have used di-block copolymers to stabilise various particles and have observed many interesting structures obtained from the self-assembly of these nanoparticles. Barium sulfate forms meso-crystals, with their shape depending on a number of factors including, $\mathrm{pH}$ and the nature of the functional groups attached to the di-block copolymer ${ }^{37,38}$.

In the presence of $p$-phosphonic acid calix[6]arene (3) barium sulfate mesocrystals appear to form, but the smaller nanoparticles cannot be individually imaged. This suggests that these particles may be fused mesocrystals or crystals formed by oriented aggregation. In addition, the lowered growth rate observed in the AFM results may be due to increased step numbers as the 2D nucleation rate rises significantly. In terms of the radial distribution of the particles in the spherical aggregate, there is no core/shell particle structure as found in ref. 38. The TEM images also suggest that the exterior of the particles are more dense than the interior, inferring that the aggregate structure may form at the expense of interior particles. This may be a ripening process and may arise from a fusion mechanism for the original nanoparticles. 
It is also interesting, albeit contradictory, that in the presence of the $p$-phosphonic acid calix[5] arene (2), small barium sulfate particles are present that do not appear to be mesocrystals. All the calixarenes have similar impacts in terms of overall crystallization behaviour (3D nucleation inhibitors, 2D nucleation promoters) and so impacts on nucleation do not appear to adequately explain the different effects of the macrocycles. In the presence of the $p$-phosphonic acid calix[5]arene, (2) the particles randomly aggregate to a relatively small size $(\sim 300 \mathrm{~nm})$. This is intriguing given that the atomic resolution images show that barium sulfate formed in the presence of both $\mathbf{1}$ and $\mathbf{2}$ have similar repeat structures when absorbed onto the barite crystal face and, therefore, they should have similar adsorption behaviour. However, a distinct feature of 2 (p-phosphonic acid calix[5] arene) is that it is amorphous, forming molecular capsules and stacks of single molecules into fibres ${ }^{32}$ at the nanometre dimensions. This is not the case for $\mathbf{1}^{29}$, which may relate to the symmetry constraints in packing five fold symmetry molecules into regular arrays. Calixarene $\mathbf{1}$ forms regular bilayers with crystallographically imposed four fold symmetry, and presumably this facilitates the assembly of particles into ordered arrays, ie mesocrystals. Nevertheless, isoelectronic $p$-sulfonatocalix[5]arene forms larger self-assembled structures with regular packing of conformationally distorted calixarenes ${ }^{40,41}$.

Thermal analysis and vibrational spectroscopy were, therefore, undertaken to try and elucidate the reasons for the differences in the calixarenes' impact. We found that in the presence of all of the additives the barium sulfate formed has three weight loss regimes (see supplementary information, SFig 7.). Barium sulfate formed in the presence of 2, 3 and $\mathbf{4}$ show the same temperature behaviour with only the magnitude of the weight loss being different. The first weight loss regime is believed to be due to adsorbed water and for all cases is between 2-4\%, some of which could be residing in the cavity of the calixarenes ${ }^{42}$. Assuming a barium sulfate particle size of $50 \mathrm{~nm}$ (diameter) and a molecular diameter for the calix[4]arene of $\sim 1 \mathrm{~nm}$, then the calculated organic mass per $100 \mathrm{~g}$ barium sulfate particles required to cover this surface would be only $3.2 \mathrm{~g}$ per $100 \mathrm{~g} \mathrm{BaSO}_{4}$. Given that the p-phosphonic acid calix[8]arene (4) has a diameter of $\sim 2 \mathrm{~nm}$ and that the others are systematically smaller, the larger diameters then result in less solids being required to cover the surface; 2.6, 2.1 and $1.6 \mathrm{~g}$ for $\mathbf{2 , 3}$ and 4 respectively. The weight loss for all of the 
barium sulfate particles formed in the presence of the various calixarene molecules is higher than that calculated to sit on the surface except for 1 where it is similar to that expected (total of $\sim 5.3 \%$, including water). This suggests that in the case of $\mathbf{1}$ the majority of the organic molecules sit on the surface of the barium sulfate particles protecting them from fusion and facilitating the formation of the mesocrystals. When 2, 3 and $\mathbf{4}$ are present, the much higher weight loss suggests that the organic molecules are incorporated within the barium sulfate structure or partitioned both within the structure and on the surface. In the case of $p$-phosphonic acid calix[8]arene (4), mesocrystal formation prevails, which suggests some regular surface adsorption of the calixarene for controlling/stabilisation the material. In the case of the $p$-phosphonic acid calix[6]arene (3) a small percentage of surface adsorption is likely but with most of the organic material incorporated within the material, leading to fusion of the originally formed mesocrystal structure. Finally, in the case of the $p$-phosphonic acid calix[5]arene (2) it can be surmised that incorporation is most significant and therefore no barrier to random aggregation exists.

Unfortunately, vibrational spectroscopy did not show any significant differences between the particles formed in the presence of the various calixarenes (supplementary information, SFig 8.) and so could not support or refute the adsorption versus incorporation hypothesis. Incorporation of molecules of this size is not unusual as dyeinclusion crystals illustrate. ${ }^{43}$ Determining the reasons for the variation in behaviour as a function of macrocycle size is difficult, particularly as the conformational flexibility increases significantly as the ring size increases. It should be noted that the behaviour of the tetramer, $\mathbf{1}$, which is the most widely studied, cannot be extrapolated directly to the larger members of the calixarene family.

\section{Conclusions}

Overall, in terms of de-supersaturation rate, the calixarenes are comparably potent in inhibiting crystallization, with the $p$-phosphonic acid calix[5]arene (2) being the most potent. Similarly, the presence of all the molecules results in barium sulfate XRD patterns showing significant line-broadening and this indicates the presence of small crystallites and/or particle size. 
Differences between the samples can readily be seen in the SEM and TEM images in the size of the particles produced; micron sized for the $p$-phosphonic acid calix[4]-, [6] and -[8]arene (1, 3 and 4) while $\leq 1 \mu \mathrm{m}$ sized particles are produced in the presence of the $p$-phosphonic acid calix[5] arene (2). TEM images show that in the case of the micron sized particles, they are clearly superstructures of smaller particles. The presence of $\mathbf{1}$ and $\mathbf{4}$ induce barium sulfate mesocrystals, which is interesting in the sense that calix[8]arenes can take on a double cone conformation, ${ }^{44}$ which is essentially equivalent to two calix[4]arenes in close proximity. The presence of 3 causes the formation of radially aligned barium sulfate nanoparticles that may have initially been mesocrystals, which fuse over time. In the case of 2 no obvious oriented self-assembly occurs after formation of the barium sulfate nanoparticles. This is despite the fact that isoelectronic $p$-sulfonated calix[5] arene form continuous selfassembled structures ${ }^{40,41}$, whereas for $\mathbf{2}$ it may be a five fold symmetry packing problem. In this context it is noteworthy that $p$-phosphonic acid calix[5] arene is amorphous, forming molecular capsules and stacks of single molecules into fibres ${ }^{32}$ at the nanometre dimensions.

Finally, we note that as the ring size increases, overall inhibition diminishes somewhat. The outlier to this trend is the $p$-phosphonic acid calix[5]arene (2). We note that the tetramer and octamer result in stable mesocrystal formation while the pentamer and hexamer do not. This may be related to whether the organic molecule adsorbs significantly on the surface rather than being incorporated into the structure, and the nature of intermolecular calixarene interactions.

The phosphonated calixarene molecules, therefore, all have subtly different impacts on barium sulfate crystallization depending on the macrocycle size, but also have many similarities, particularly in their impact on 2 and 3 dimensional nucleation rates. The relationship between the additive structure, and the stability of mesocrystals, appears to be subtle, and the choice of $p$-phosphonic acid calix[n]arene for controlling the crystallisation is critical, and requires further investigation.

\section{Acknowledgements}

We would like to thank Peter Chapman for the TGA analysis and acknowledge the Curtin Centre for Materials Research for use of the SEM, TEM and XRD facilities. 
We would also like to acknowledge Dr. Thomas Becker for the use of the AFM facilities and the Australian Research Council for support of the work.

Supporting Information: Expanded Figure 1, further TEM images of solids formed in the presence of the various calixarenes, SEM image of the barium sulfate particles formed in the presence of the calix[8]arene and used for XRD analysis, absorbance versus time data for the calix[4]arene, further AFM data on barium sulfate in the presence of the calix[5]- and -[8]arene, thermal analysis and FTIR spectra for barium sulfate solids formed in the presence of the different calixarenes. This information is available free of charge via the Internet at http://pubs.acs.org/.

\section{References}

1. Wibowo, C.; Ng, K. M. AIChE J. 2000, 46, 1400-1421.

2. Mann, S. In Biomineralization: Principles and Concepts in Bioinorganic Materials Chemistry; Mann, S. Eds; Oxford University Press, ISBN 0198508824, 2001; pp 1-24.

3. Weiner, S.; Addadi, L. Journal of Materials Chemistry 1997, 7(5), 689-702.

4. Wilson, A. H. Journal of Petrology 1992, 33(3), 611-663.

5. Morse, J. W.; Casey, W. H., Am. J. Sci. 1988, 288(6), 537-560.

6. Weiner, S.; Addadi, L. Biochemistry in Israel 1991, TIBS 16, 252-256.

7. Heo, S. I.; Yun, J. C.; Oh, K. S.; Han, K. S., Advanced Composite Materials 2006, 15(1), 115-126.

8. Podczeck, F.; Mia, Y., International Journal of Pharmaceutics 1996, 144(2), 187-194.

9. Cölfen, H.; Qi, L. Chem. Eur. J. 2001, 7(1), 107-116.

10. Jones, F.; Ogden, M. I. CrystEngComm. 2010, 12, 1016-1023.

11. Jones, F.; Jones, P.; Ogden, M. I.; Richmond, W. R.; Rohl, A. L.; Saunders, M. Journal of Colloids and Interface Science 2007, 316, 553-561.

12. Massi, M.; Radomirovic, T.; Ogden, M. I.; Jones, F. CrystEngComm 2010, 12, 4205-4207.

13. Coveney, P. V.; Davey, R. J.; Griffin, J. L. W.; He, Y.; Hamlin, J. D.; Stackhouse, S.; Whiting, A. J. Am. Chem. Soc. 2000, 122, 11557-11558. 
14. Jones, F.; Clegg, J.; Oliviera, A.; Rohl, A. L.; Ogden, M. I.; Parkinson, G. M.; Fogg, A. M.; Reyhani, M. M. CrystEngComm. 2001, 3(40), 165-167.

15. Bosbach, D.; Coveney, P. V.; Griffin, J. L. W.; Putnis, A.; Risthaus, P.; Stackhouse, S.; Whiting, A. J. Chem. Soc., Perkin Trans. 2002, 2, 1236-1245.

16. Baynton, A.; Radomirovic, T.; Ogden, M. I.; Raston, C. L.; Richmond, W. R.; Jones, F. CrystEngComm. 2011, 13, 109-112.

17. Schwarzer, H.-C.; Peukert, W. Chem. Eng. Technol. 2002, 25, 657-661.

18. Graham, G. M.; Boak, L. S.; Sorbie, K. S. Int. Symp. Oilfield Chem.; Society of Petroleum Engineers: USA, 1997, 611-626.

19. Bertram, M.; Cowen, J., Aquatic Geochem. 1998, 4, 455-468.

20. Hopwood, J. D.; Mann, S.; Gooday, A. J. Mar. Biol. Ass. UK 1997, 77, 969-987.

21. Sanchez-Moral, S.; Luque, L.; Canaveras, J.; Laiz, L.; Jurado, V.; Hermosin, B.; Saiz-Jimenez, C. Ann. Microbiol. 2004, 54, 1-12.

22. Monnin, C.; Cividini, D. Geochimica et Cosmochimica Acta 2006, 70, 3290-3298.

23. Bernstein, R. E.; Byrne, R. H. Marine Chemistry 2004, 86, 45-50.

24. Eggers, P. K.; Becker, T.; Melvin, M. K.; Boulos, R. A.; James, E.; Morellini, N.; Harvey, A. R.; Dunlop, S. A.; Fitzgerald, M.; Stubbs, K. A.; Raston, C. L. RSC Advances 2012, 2, 6250-6257.

25. Martin, A. D.; Raston, C. L. Chem. Commun. 2011, 47, 9764-9772.

26. Goh, C. Y. ; Becker, T.; Brown, D. H.; Skelton, B. W.; Jones, F.; Mocerino, M.; Ogden, M. I. ChemComm. 2011, 47, 6057-6059; Becker, T.; Goh, C. Y.; Jones, F.; M. J. McIldowie, Mocerino, M.; Ogden, M. I. ChemComm. 2008, 3900-3902.

27. Jones, F.; Mocerino, M.; Ogden, M. I.; Oliveira A.; Parkinson G. M. Cryst Growth \& Design 2005, 5(6), 2336-2343.

28. Baynton, A.; Ogden, M. I.; Raston, C. L.; Jones, F. CrystEngComm 2012, 14 , 1057-1062.

29. Clark, T. E.; Makha, M.; Sobolev, A. N.; Su, D.; Rohrs, H.; Gross, M. L.; Atwood, J. L.; Raston, C. L. New J. Chem., 2008, 32, 1478-1483.

30. Yang, K. C.; Hogg, R., Analytical Chemistry 1979, 51(6), 758-763.

31. Mullin, J. W. In Crystallization, 3rd edition; Mullin, J. W. Eds; ButterworthHeinemann: Oxford, 1961; pp 172-201.

32. Martin, A. D.; Boulos, R. A.; Hubble, L. J.; Hartlieb, K. J.; Raston, C. L. ChemComm. 2011, 47, 7353-7355. 
33. Houmadi, S.; Coquière, D.; Legrand, L.; Faurè, M. C.; Goldmann, M.; Reinaud, O.; Rèmita S., Langmuir 2007, 23, 4849-4855.

34. Clark, T. E.; Martin, A.; Makha, M.; Sobolev, A. N.; Su, D.; Rohrs, H. W.; Gross, M. L.; Raston C. L. Cryst. Growth \& Design 2010, 10, 3211-3217.

35. Niederberger, M.; Cölfen, H. Phys. Chem. Chem. Phys. 2006, 8, 3271.

36. H. Cölfen, M. Antonietti In Mesocrystals and Nonclassical Crystallization; Cölfen, H.; Antonietti, M. Eds.; John Wiley and Sons, Chichester, U.K., 2008; Chapter 7, pp 113-179.

37. Qi, L.; Cölfen, H.; Antonietti, M. Angew. Chem. Int. Ed. 2000, 39, 604.

38. Qi, L.; Cölfen, H.; Antonietti, M. Chem. Mater. 2000, 12, 2392-2403.

39. Song, R-Q.; Cölfen, H.; Xu, A-W.; Hartmann, J.; Antonietti, M. ACS Nano 2009, 3(7), 1966-78.

40. Atwood, J. L.; Barbour, L. J.; Hardie, M. J.; Raston C. L. Coord. Chem. Rev. 2001, $222,3-32$.

41. Dalgarno, S. J.; Warren, J. E.; Atwood, J. L.; Raston, C. L. New J, Chem. 2008, 32, 2100-2107.

42. Clark, T. E.; Makha, M.; Sobolev, A. N.; Rohrs, H.; Atwood, J. L.; Raston, C. L. Chem. Eur. J. 2008, 14, 3931-3938.

43. Kahr, B.; Gurney, R. W. Chem. Rev. 2001, 101, 893-951.

44. Smith, C. B.; Barbour, L. J.; Mahka, M.; Raston, C. L.; Sobolev, A. N. New J. Chem. 2006, 30, 991-996. 
For Table of Contents Use Only

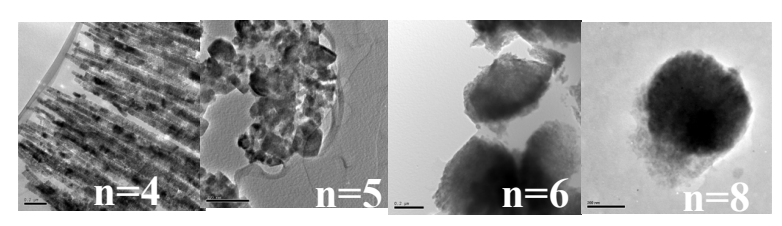

Additive $=p$-phosphonic acid calix $[\mathrm{n}]$ arene

The crystallization of barium sulfate is significantly altered when phosphonated calixarene molecules are present but their impact, while dependant on the ring size, is not easily predicted. 